\title{
Social acknowledgement as a predictor of post-traumatic stress and complicated grief after witnessing assisted suicide
}

International Journal of Social Psychiatry 58(4) 38I-385 (C) The Author(s) 2011 Reprints and permissions: sagepub.co.uk/journalsPermissions.nav DOI: |0.| |77/00207640 | |40079| isp.sagepub.com (S)AGE

\author{
Birgit Wagner, ' Valerie Keller, ${ }^{2}$ Christine Knaevelsrud ${ }^{3}$ and \\ Andreas Maercker ${ }^{4}$
}

\begin{abstract}
Background: In Switzerland, right-to-die organizations such as Exit Deutsche Schweiz offer suicide assistance to their members. However, there is limited knowledge of the impact that witnessing assisted suicide has on the post-traumatic stress severity or the grief process of family members. Low perceived social acknowledgement may affect mental health. Methods: A cross-sectional survey of 85 family members who were present at an assisted suicide was conducted in December 2007. The Inventory of Complicated Grief and the Impact of Event Scale were used to assess symptoms of post-traumatic stress disorder (PTSD) and complicated grief (CG) at I4 to 24 months post-loss. Further, the Social Acknowledgement Questionnaire was used to examine the impact that the social environment's acknowledgement of the end-of-life decision had on respondents' mental health.

Results: As expected, social acknowledgement as a survivor was related to PTSD symptoms and CG. In particular, perceived general disapproval was strongly correlated with all outcome measures, whereas recognition was not significantly related to PTSD or CG (intrusion and avoidance).

Conclusion: Family members of patients who use assisted suicide may hesitate to disclose the manner of death, and the community and societal environment may express strong views concerning the end-of-life decision. This can lead to increased levels of PTSD and CG.
\end{abstract}

\section{Keywords}

assisted suicide, complicated grief, euthanasia, post-traumatic stress disorder, social acknowledgement

\section{Background}

Assisted suicide is punishable by law nearly everywhere except in Switzerland, the Netherlands, and the states of Oregon and Washington in the USA. According to Swiss law, assisting suicide is legal as long as a selfish motive cannot be established. Physicians in Switzerland are therefore allowed to prescribe or supply a lethal dose of barbiturates with the explicit intention of enabling a patient they have examined to end his or her own life. However, most assisted suicides in Switzerland are conducted with the assistance of non-profit organizations (Ziegler and Bosshard, 2007).

The two largest right-to-die organizations in Switzerland are Exit Deutsche Schweiz and Dignitas. Exit Deutsche Schweiz has about 50,000 members (about $1 \%$ of the Swiss population), and between 100 and 150 people die each year with the organization's assistance. Usually, the suicide takes place at the patient's home. After the patient has died, the Exit volunteer notifies the police: cases of assisted suicide are treated as extraordinary deaths and the authorities must investigate each case. The police and medical officer usually release the body at the scene and close the case.
Family members' responses to assisted suicide may be highly ambivalent. On the one hand, they may want to respect the patient's desire to end the suffering. On the other, they may find that the patient's wishes are in conflict with their own beliefs or moral convictions. Although the legal and ethical aspects of assisted suicide are widely discussed, little is known about how it affects the mental health

\footnotetext{
' University Clinic for Psychotherapy and Psychosomatic Medicine, University Hospital Leipzig, Germany

${ }^{2}$ Department of Clinical Psychology, Psychotherapy and Psychoanalysis, University of Zurich, Switzerland

${ }^{3}$ Department of Clinical Psychology, Free University Berlin, Germany

${ }^{4}$ Department of Psychopathology and Clinical Intervention, University of Zurich, Switzerland
}

\section{Corresponding author:}

Birgit Wagner, University Clinic for Psychotherapy and Psychosomatic Medicine, University Hospital Leipzig, Semmelweisstr. 10, 04103 Leipzig, Germany

Email: birgit.wagner@medizin.uni-leipzig.de 
of family members who witness the assisted death of a significant other. Data obtained from Swiss respondents who witnessed the death of a close family member through assisted suicide indicate that the experience can have a serious impact on mental health, especially on depression and on post-traumatic stress symptoms related to the death (Wagner, Müller, \& Maercker, 2011). Some 13\% of the family members surveyed met the criteria for full post-traumatic stress disorder (PTSD) and 6.5\% met the criteria for subthreshold PTSD. The prevalence of depression was $16 \%$; that of anxiety was $6 \%$. Moreover, $4.9 \%$ of the participants met the diagnostic criteria for complicated grief (CG) (Wagner et al., in press).

A large body of research has addressed social factors as predictors of PTSD (Lerias and Byrne, 2003). Specifically, a lack of social support has been found to predict the development of PTSD (Brewin et al., 2000). However, other social factors, such as negative reactions of others and interpersonal recognition as a trauma victim, seem to play an even more significant role in the development of PTSD (Forstmeier et al., 2009; Maercker et al., 2009). Solomon et al. (1989) were among the first to show that low societal appreciation of Israeli soldiers returning from the Lebanon war was related to more severe post-traumatic symptomatology. Studies with American soldiers returning from Vietnam reported similar results (Fontana and Rosenheck, 1994).

Based on these findings, Maercker and Müller (2004) proposed the concept of 'social acknowledgement'. Social acknowledgement in the context of PTSD is defined as a victim's experience of positive reactions from society that show appreciation of the victim's traumatic experience and acknowledge the difficulty of their situation (Müller et al., 2008). In contrast, social disapproval and criticism causes survivors to feel unsupported or otherwise alienated from their environment (Lepore et al., 1996). Ideally, survivors of a traumatic event receive unconditional support from the inner circle of family and friends, followed by the outer circle of acquaintances, neighbours and community members (Maercker et al., 2009). Whereas social support is defined as the degree of emotional and instrumental support received from the direct environment, social (or societal) acknowledgement expands this definition to encompass the broader societal context (Maercker and Müller, 2004). The construct of social acknowledgement has been crossculturally validated in a number of studies with trauma survivors (Forstmeier et al., 2009; Maercker and Müller, 2004; Maercker et al., 2009; Müller et al., 2008, 2009). Empirical studies have found that a subjective lack of social acknowledgement predicts higher trauma-related symptoms (Maercker and Müller, 2004) and may impact how trauma survivors process their traumatic experiences emotionally and cognitively (Jones et al., 2006).

Family members of patients who decide on assisted suicide may hesitate to disclose the manner of death; the community and societal environment may express strong views on the end-of-life decision. Legal investigations after the death and active disapproval of the end-of-life decision may increase feelings of having done something wrong. Beyond the ongoing political and legal discussions about right-to-die issues, it is thus important to understand the psychological effects of assisted suicide on bereaved family members. In this study, we therefore examined the effects of perceived social acknowledgement on symptoms of post-traumatic stress and CG.

\section{Methods}

\section{Study design and sample}

In November 2007, we conducted a cross-sectional study in cooperation with the right-to-die organization Exit Deutsche Schweiz. Exit's records of all deaths by assisted suicide include information on those present at the death. We identified 146 people who had died with the support of the organization between October 2005 and September 2006. Of this group, 21 had died with no family members as witnesses. In 14 cases, the addresses of the witnesses were not recorded. A total of 229 relatives were recorded as being present at the death of the remaining 111 deceased persons. We attempted to contact these witnesses by mail, asking them to complete and return an anonymous written questionnaire. Correct mailing addresses were available for only 167 witnesses. Of the 167 immediate family members (partner, parent, child or sibling) who were eligible for the study, four refused to participate, 78 did not respond and 85 (51\%) returned the questionnaire.

\section{Measurement of outcomes}

Beside demographic items, the questionnaire contained standard self-report measures to assess the prevalence of symptoms of PTSD and CG in respondents. The demographic variables assessed included respondents' age, gender, educational level, marital status and employment status. Further, we assessed variables regarding the deceased person (e.g. time since death, age at death, duration of disease, medical diagnosis).

Post-traumatic stress disorder: Symptoms of PTSD were evaluated using the Impact of Event Scale-Revised (IES-R; Weiss and Marmar, 1997) in its German translation (Maercker and Schützwohl, 1998). This 22-item measure specifically assessed the extent to which respondents were distressed by witnessing the death of their loved one and related symptoms of intrusion, avoidance and arousal experienced in the previous week on a four-point Likert scale $(0,1,3,5)$. Internal consistency in our sample was $\alpha=0.85$ for Intrusion, $\alpha=$ 0.81 for Avoidance and $\alpha=0.87$ for Hyperarousal.

Complicated grief: CG was measured using the Inventory of Complicated Grief-SF (ICG; Prigerson and Jacobs, 2001). The original ICG comprises 34 items. Our 
short version (for details, see Forstmeier and Maercker, 2007) included only items assessing the refined consensus criteria (Prigerson and Jacobs, 2001; Prigerson et al., 1999): one on the triggering event (death of a significant other; criteria A1), four on separation distress (criterion A2), eight on traumatic distress (criterion $\mathrm{B}$ ), one on duration of more than six months (criterion C), and one on disturbance causing clinically significant impairment (criterion D). A reduced four-point response scale $(1=$ no/never to $4=$ always) was applied. Internal consistency in this sample was $\alpha=0.81$ for the Separation Distress subscale and $\alpha=$ 0.82 for the Traumatic Distress subscale.

Social acknowledgement: Social acknowledgement was measured by the Social Acknowledgement as a Victim or Survivor Questionnaire (SAQ; Maercker and Müller, 2004), which assesses the degree to which people feel validated and supported by their social environment following a traumatic event. The 16 items are clustered into three subscales: Recognition (six items), General Disapproval (five items) and Family Disapproval (five items). The answers are rated on a six-point Likert scale from denial (0) to agreement (5). Internal consistency in this sample was $\alpha=0.65$ for the Recognition subscale, $\alpha=0.79$ for the General Disapproval subscale, $\alpha=0.80$ for the Family Disapproval subscale, and $\alpha=0.75$ overall.

\section{Results}

\section{Demographic characteristics}

The sample consisted of 48 women $(56 \%)$ and 37 men (Table 1). Ages ranged from 25 to $89(M=60.15$, SD 13.42). In terms of highest educational levels, 6 respondents $(7 \%)$ had completed primary education, 45 (53\%) had completed secondary education, $26(31 \%)$ had a university degree and $8(9 \%)$ had a doctoral degree. The largest group $(47 \% ; n=$ $40)$ was grieving the death of a parent; $33 \%(n=28)$ had lost a spouse/partner; $2 \%(n=2)$ a child; and $18 \%(n=15)$ a sibling or close friend. The average time since death at the point of assessment was about 20 months. Of the deceased, $52 \%$ had been diagnosed with cancer, $36 \%$ with age-related, non-fatal medical conditions; $14 \%$ with cardiac disease; $6 \%$ with beginning Alzheimer's/dementia; and 3\% with mental disorders. Prevalence of PTSD and CG in the sample are reported elsewhere (Wagner, Müller, \& Maercker, 2011).

\section{Social acknowledgement and mental health}

Table 2 reports descriptive findings on perceived social acknowledgement in the whole sample and by gender. No significant gender differences were found.

We calculated Pearson correlations to examine the relationship of social acknowledgement with PTSD and CG (Table 3). We found significant correlations between the General Disapproval subscale and all PTSD symptoms ( $r \mathrm{~s}$
Table I. Characteristics of study participants and deceased persons $(N=85)$

\begin{tabular}{|c|c|}
\hline Characteristics & $n(\%)$ \\
\hline \multicolumn{2}{|l|}{ Study participants } \\
\hline Age, in years: $M$ (SD; range) & $60.15(13.42 ; 25-89)$ \\
\hline \multicolumn{2}{|l|}{ Sex } \\
\hline Men & $37(43)$ \\
\hline Women & $48(56)$ \\
\hline \multicolumn{2}{|l|}{ Marital status } \\
\hline Single & $6(7)$ \\
\hline Married & $47(55)$ \\
\hline Widowed & $26(3 \mathrm{I})$ \\
\hline Divorced & $6(7)$ \\
\hline \multicolumn{2}{|l|}{ Highest educational level } \\
\hline Primary education & $6(7)$ \\
\hline Secondary education & $45(53)$ \\
\hline University degree & $26(31)$ \\
\hline Doctoral degree & $8(9)$ \\
\hline \multicolumn{2}{|l|}{ Deceased's relationship to respondent } \\
\hline Father/mother & $40(47)$ \\
\hline Partner & $28(33)$ \\
\hline Child & $2(2)$ \\
\hline Sibling/friend & $15(18)$ \\
\hline \multicolumn{2}{|l|}{ Deceased persons } \\
\hline Time since death, in months: $M(S D)$ & $19.73(4)$ \\
\hline Age, in years: $M(S D)$ & $77.36(13.91)$ \\
\hline \multicolumn{2}{|l|}{ Gender } \\
\hline Men & $44(52)$ \\
\hline Women & $41(48)$ \\
\hline \multicolumn{2}{|l|}{ Medical diagnosis } \\
\hline Cancer & $44(52)$ \\
\hline Non-fatal age-related diseases & $31(36)$ \\
\hline Cardiac disease & $12(14)$ \\
\hline Alzheimer's/dementia & $5(6)$ \\
\hline Mental disorder & $3(3)$ \\
\hline
\end{tabular}

$=0.50-0.56)$. The Recognition and Family Disapproval subscales showed significant correlations with the IESHyperarousal scale $(r \mathrm{~s}=0.33-0.34)$, but not with symptoms of intrusion or avoidance. In a multiple regression analysis, the social acknowledgement factors explained $24 \%$ (adjusted $R^{2}$ ) of the variance in scores on the IES (Table 4). However, only the General Disapproval subscale was significant and explained most of the variance.

Both subscales of the ICG showed significant positive correlations with the General Disapproval subscale $(r \mathrm{~s}=$ $0.63-0.71)$ and the Family Disapproval scale $\left(r_{s}=0.32\right.$ 0.33 ), but not with the Recognition subscale. Therefore, General Disapproval seems to have the strongest impact on both PTSD and CG.

\section{Discussion}

Poor social integration and low societal appreciation can affect recovery after traumatic and difficult life events. The results of this cross-sectional study replicated previous findings and showed that social acknowledgement predicts PTSD symptom severity and CG. Specifically, the perceived disapproval of the social environment was related to 
Table 2. Mean social acknowledgement scores

\begin{tabular}{lccrr}
\hline & Full sample $M(\mathrm{SD})(N=85)$ & Male $M(\mathrm{SD})(n=37)$ & Female $M(\mathrm{SD})(n=48)$ & $\begin{array}{l}t \text {-test for gender } \\
\text { differences }(p)\end{array}$ \\
\hline Recognition $(n=39)$ & $9.41(3.60)$ & $9.63(3.64)$ & $9.11(3.63)$ & -0.44 \\
General Disapproval $(n=65)$ & $3.27(3.52)$ & $3.03(3.06)$ & $3.50(3.93)$ & 0.53 \\
Family Disapproval $(n=68)$ & $-0.88(2.66)$ & $-1.34(2.04)$ & $-0.47(3.09)$ & 1.35 \\
\hline
\end{tabular}

Table 3. Intercorrelations between PTSD, CG and social acknowledgement

\begin{tabular}{|c|c|c|c|c|c|c|c|c|}
\hline & I & 2 & 3 & 4 & 5 & 6 & 7 & 8 \\
\hline I. IES-R-Intrusion & I & & & & & & & \\
\hline 2. IES-R-Avoidance & $0.64 * *$ & I & & & & & & \\
\hline 3. IES-R-Hyperarousal & $0.67 * *$ & $0.68 * *$ & I & & & & & \\
\hline 4. ICG-Separation Distress & $0.61 * *$ & $0.53 * *$ & $0.73 * *$ & I & & & & \\
\hline 5. ICG-Traumatic Distress & $0.55^{* *}$ & $0.52 * *$ & $0.76 * *$ & $0.74 * *$ & I & & & \\
\hline 6. SAQ-Recognition & 0.13 & -0.13 & $0.34 *$ & -0.17 & 0.04 & I & & \\
\hline 7. SAQ-General Disapproval & $0.52 * *$ & $0.50 * *$ & $0.56 * *$ & $0.7 I^{* *}$ & $0.63^{* *}$ & 0.04 & I & \\
\hline 8. SAQ-Family Disapproval & 0.18 & 0.23 & $0.33 * *$ & $0.33 * *$ & $0.32 * *$ & $-0.45 * *$ & $0.6 I^{* *}$ & \\
\hline
\end{tabular}

Note: IES-R: Impact of Event Scale-Revised; ICG: Inventory of Complicated Grief; SAQ: Social Acknowledgement Questionnaire.

$* p<0.05, * * p<0.01$

Table 4. Predicting scores on the Impact of Event Scale: Results of a multiple regression analysis

\begin{tabular}{lrrr}
\hline & B & SE B & \multicolumn{1}{l}{$\beta$} \\
\hline Recognition $(n=39)$ & -0.345 & 0.619 & \multicolumn{1}{l}{-0.100} \\
General Disapproval $(n=65)$ & 1.922 & 0.680 & $0.562^{* *}$ \\
Family Disapproval $(n=68)$ & -0.074 & 1.078 & -0.015
\end{tabular}

** $p=0.008, R=0.557$, adjusted $R^{2}=0.24$

higher PTSD and CG symptoms. In addition, family disapproval was strongly related to CG processes. Recognition, in contrast, was not related to CG symptomatology or to the PTSD symptoms of intrusion and avoidance. These findings confirm the results of previous studies with crime victims (Müller et al., 2008) and the results of a meta-analysis (Brewin et al., 2000). Although perceived lack of social support is one of the strongest predictors of PTSD, the perception of social support did not necessarily promote positive outcomes in our sample. However, only $45 \%$ of respondents completed the items of the Recognition subscale. This response rate is surprisingly low relative to the other two subscales of the SAQ ( $76 \%$ vs $80 \%$ ). The items of the Recognition subscale included statements such as 'My friends shared my experience with me', 'My friends' reactions were supportive' and 'My colleagues/boss understood why I didn't come to work'. Many of the participants stated that they had not talked to friends, colleagues, priests or neighbours about the way their loved one had died, meaning that they were unable to answer questions specifically relating to the reactions of their social environment. The extent to which participants' experiences are denied or invalidated by their family or societal environment may have an important effect on their psychological adaptation to the traumatic stressor (Maercker and Müller, 2004).

These findings suggest that coping with death by assisted suicide can be complicated by the feeling that society will disapprove of the decision. The participants in this study may have experienced a sense of disapproval and isolation from their social environment, potentially as a result of the ongoing media and legal discussion of right-to-die issues, the underlying tone of which is often negative.

\section{Limitations}

Our study has several limitations. First, we did not include a control group of respondents who had lost a loved one by natural death, so we cannot determine whether levels of $\mathrm{CG}$ would be similar in a matched control group. A prospective longitudinal study would provide better insights into time effects in the long-term symptoms of CG. Further, we were able to recruit only about half of the family members of individuals who died during the study period, and were not able to determine the prevalence of CG in non-participating family members or indeed other differences between the participating and non-participating groups.

\section{Conclusion}

To date, there has been little research on the aftermath of losing a significant person through assisted suicide or euthanasia. In this study, we examined the impact of perceived social acknowledgement on post-traumatic stress symptom severity and the grief process after assisted suicide. Scores on the General Disapproval subscale were 
substantially positively correlated with PTSD symptoms and $\mathrm{CG}$, suggesting that survivors who do not receive social acknowledgement experience more mental health problems in the aftermath of the death. In conclusion, the findings suggest that perceived general disapproval seems to be an important factor predicting PTSD symptoms and CG in the family of patients who choose assisted suicide. The implications for clinical practice are that acknowledgement may promote recovery and that a focus on disclosure of the experience of having witnessed an assisted suicide may have a positive influence on the healing process. Further research is needed to clarify these preliminary findings.

\section{References}

Brewin, C.R., Andrews, B. and Valentine, J.D. (2000) 'MetaAnalysis of Risk Factors for Posttraumatic Stress Disorder in Trauma-Exposed Adults.' Journal of Consulting and Clinical Psychology 68: 748-66.

Fontana, A. and Rosenheck, R. (1994) 'Posttraumatic Stress Disorder among Vietnam Theater Veterans. A Causal Model of Etiology in a Community Sample.' Journal of Nervous and Mental Diseases 182: 677-84.

Forstmeier, S., Kuwert, P., Spitzer, C., Freyberger, H.J. and Maercker, A. (2009) 'Posttraumatic Growth, Social Acknowledgment as Survivors, and Sense of Coherence in Former German Child Soldiers of World War II.' American Journal of Geriatric Psychiatry 17: 1030-9.

Forstmeier, S. and Maercker, A. (2007) 'Comparison of Two Diagnostic Systems for Complicated Grief.' Journal of Affective Disorders 99(1-3): 203-11.

Jones, B., Muller, J. and Maercker, A. (2006) 'Trauma and Posttraumatic Reactions in German Development Aid Workers: Prevalences and Relationship to Social Acknowledgement.' International Journal of Social Psychiatry 52: 91-100.

Lepore, S.J., Silver, R.C., Wortman, C.B. and Wayment, H.A. (1996) 'Social Constraints, Intrusive Thoughts, and Depressive Symptoms among Bereaved Mothers.' Journal of Personality and Social Psychology 70: 271-82.

Lerias, D. and Byrne, M. (2003) 'Vicarious Traumatization: Symptoms and Predictors.' Stress and Health 19: 129-38.
Maercker, A. and Müller, J. (2004) 'Social Acknowledgment as a Victim or Survivor: A Scale to Measure a Recovery Factor of PTSD.' Journal of Traumatic Stress 17: 345-51.

Maercker, A., Povilonyte, M., Lianova, R. and Pöhlmann, K. (2009) 'Is Acknowledgment of Trauma a Protective Factor?' European Psychologist 14: 249-54.

Maercker, A. and Schützwohl, M. (1998) 'Erfassung von psychischen Belastungsfolgen: Die Revision der Impact of Event-Skala [Assessing Effects of Traumatic Events: The Impact of Event Scale-Revised].' Diagnostica 44: 130-41.

Müller, J., Moergeli, H. and Maercker, A. (2008) 'Disclosure and Social Acknowledgement as Predictors of Recovery From Posttraumatic Stress: A Longitudinal Study in Crime Victims.' Canadian Journal of Psychiatry 53: 160-8.

Müller, J., Orth, U., Wang, J. and Maercker, A. (2009) 'Disclosure Attitudes and Social Acknowledgement as Predictors of Posttraumatic Stress Disorder Symptom Severity in Chinese and German Crime Victims.' Canadian Journal of Psychiatry 54: $547-56$.

Prigerson, H.G. and Jacobs, S.C. (2001) 'Traumatic Grief as a Distinct Disorder: A Rationale, Consensus Criteria, and a Preliminary Empirical Test', in M.S. Stroebe, W. Stroebe, R.O. Hansson and H. Schut (eds) Handbook of Bereavement Research: Consequences, Coping, and Care. Washington, DC: American Psychological Association

Prigerson, H.G., Shear, M.K., Jacobs, S.C., Reynolds, C. F., III, Maciejewski, P.K., Davidson, J.R. et al. (1999) 'Consensus Criteria for Traumatic Grief. A Preliminary Empirical Test.' British Journal of Psychiatry 174(1): 67-73.

Solomon, Z., Mikulincer, M. and Flum, H. (1989) 'The Implications of Life Events and Social Integration in the Course of Combat-Related Post-Traumatic Stress Disorder.' Social Psychiatry and Psychiatric Epidemiology 24(1): 41-8.

Wagner, B., Müller, J. and Maercker, A. (2011) 'Death by Request in Switzerland: PTSD and Complicated Grief after Witnessing Assisted Suicide.' Epub ahead of print. European Psychiatry.

Weiss, D.S. and Marmar, C.R. (1997) 'The Impact of Event Scale-Revised,' in J. Wilson and T.M. Keane (eds) Assessing Psychological Trauma and PTSD. New York, NY: Guildford Press.

Ziegler, S.J. and Bosshard, G. (2007) 'Role of Non-Governmental Organizations in Physician-Assisted Suicide.' British Medical Journal 334(7588): 295-8. 